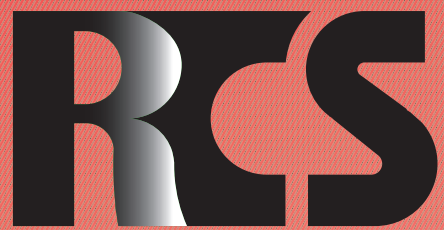

Depósito legal ppi $201502 Z U 4662$

Esta publicación científica en formato digital es continuidad de la revista impresa Depósito Legal: pp $197402 Z U 789$

- ISSN: 1315-9518 • ISSN-E: 2477-9431

Revista de Ciencias Sociales

Universidad del Zulia. Revista de la Facultad de Ciencias Económicas y Sociales Vol. XXVII. No. 2

Abril-Junio 2021

Esta publicación científica en formato digital es continuidad de la revista impresa Depósito Legal: pp $197402 Z$ Z789 ISSN: 1315-9518 

creolización, sincretismo e hibridación cultural, a través de los mercados populares en América. Revista de Ciencias Sociales (Ve), XXVII(2), 322-

\title{
Mestizaje, creolización, sincretismo e hibridación cultural, a través de los mercados populares en América
}

\author{
Ángel-Bravo, Rafael*
}

\section{Resumen}

Los mercados populares en el continente americano, especialmente en América Latina, ayudan a la comercialización de muchos de estos productos y la conservación de diversas expresiones populares, tradicionales y folklóricas, frente a los efectos homogeneizadores de la globalización y la modernidad. Con base en la observación directa y revisión de diversos referentes teóricos, utilizando la fotografía como instrumento para la recolección y registro documental, se busca comprender y analizar cómo estos fenómenos se materializan y se evidencian dentro de los mercados populares, espacios que se revalúan como núcleos de preservación cultural. A partir de la expansión europea hacia el continente americano, con la llegada de navegantes y colonizadores, sumada a posteriores movimientos migratorios, voluntarios y forzados, se desarrolla una serie de procesos interculturales como el mestizaje, creolización, hibridación y el sincretismo, los cuales conducen a una configuración o reconfiguración de identidades culturales, que se hacen manifiestas a través de diversas expresiones del folklore en sus distintas categorías, tradiciones, creencias, costumbres y manifestaciones artísticas, materializadas gracias a la herencia alimentaria, artefactos decorativos y utilitarios, iconografía religiosa, amuletos y gran diversidad de productos, principalmente artesanales. Se concluye, que esta conjugación de saberes, son preservados en estos espacios de intercambio comercial y social.

Palabras clave: Mercados populares; mestizaje; hibridación; creolización; sincretismo.

Máster en Comunicación Empresarial y Corporativa. Docente de la Corporación Universitaria Autónoma de Nariño, Colombia. E-mail: angelrafael1980@hotmail.com iD ORCID: https://orcid.org/0000-0001-6326-6787 


\title{
Miscegenation, creolization, syncretism and cultural hybridization, through popular markets in America
}

\begin{abstract}
Popular markets in the American continent, especially in Latin America, help the commercialization of many of these products and the preservation of various popular, traditional and folk expressions, in the face of the homogenizing effects of globalization and modernity. Based on the direct observation and review of various theoretical references, using photography as an instrument for the collection and documentary record, it seeks to understand and analyze how these phenomena materialize and become evident within popular markets, spaces that are revalued as nuclei of cultural preservation. From the European expansion towards the American continent, with the arrival of navigators and colonizers, added to later migratory, voluntary and forced movements, a series of intercultural processes developed such as miscegenation, creolization, hybridization and syncretism, which lead to a configuration or reconfiguration of cultural identities, which are made manifest through various expressions of folklore in their different categories, traditions, beliefs, customs and artistic manifestations, materialized thanks to food inheritance, decorative and utilitarian artifacts, religious iconography, amulets and a great diversity of products, mainly handmade. It is concluded that this conjugation of knowledge is preserved in these spaces of commercial and social exchange.
\end{abstract}

Keywords: Popular markets; miscegenation; hybridization; creolization; syncretism.

\section{Introducción}

A partir del descubrimiento y conquista del continente americano, los procesos de migración y otros desplazamientos humanos, forzados o voluntarios, motivados por diversos factores históricos, sociales y económicos, entre otros, dan lugar a una gran diversidad de encuentros y fenómenos interculturales, entre los cuales se pueden identificar el mestizaje, la creolización, la hibridación y el sincretismo, los cuales se generan gracias al encuentro de diferentes culturas, tradiciones, prácticas, costumbres y creencias, motivando una configuración o reconfiguración de identidades regionales, nacionales, étnicas y socioculturales, las cuales se desarrollan a través de las regiones Norte, Centro y Sur de América.

Estos fenómenos culturales, se evidencian a través de las diversas expresiones del patrimonio material e inmaterial, el cual se transforma y evoluciona gracias a estos procesos de intercambio, mestizaje e hibridación, los cuales determinan la diversidad cultural de este continente, que se forja como un crisol de razas y culturas, desde la llegada de población europea y africana, a partir del siglo XVI, para hacer de los pueblos y ciudades, un reflejo de esta multiculturalidad, como de la herencia aborigen, la cual se hace latente en los llamados mercados populares y otros espacios, en contextos rurales así como urbanos (ver Figura I). 


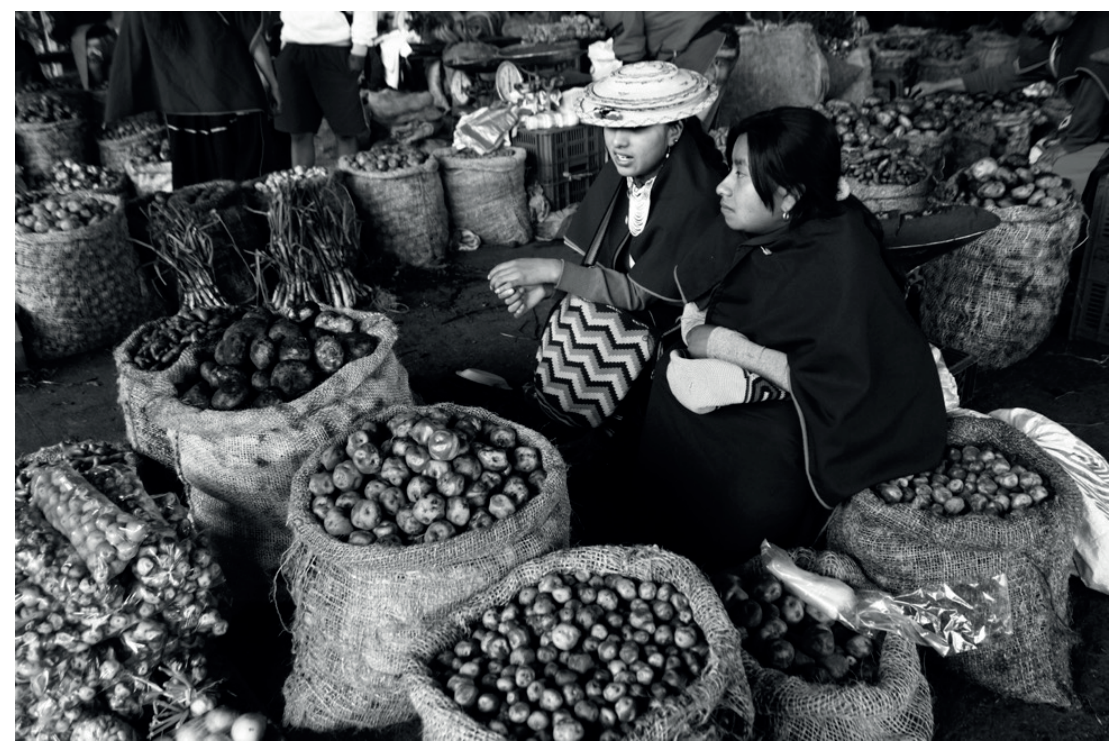

Fuente: Elaboración propia, 2017.

\section{Figura I: Integrantes de la comunidad indígena Misak ofrecen sus productos en el mercado central. Silvia, Cauca, Colombia}

En ese sentido, García (2005) plantea que la hibridación, es un fenómeno que ha generado una preocupación tardía, cuando esta ha sido una característica permanente en el desarrollo histórico, a través del tiempo. De acuerdo con el autor, si bien el mestizaje ha sido considerado un factor fundamental en el desarrollo de las sociedades, el concepto de "hibridación" ha sido usado para identificar todo lo ocurrido tras la expansión europea hacia el continente americano en el siglo XV, mientras que en algunos casos como el de Bakhtin, lo utilizan con el fin de caracterizar "la coexistencia, desde el comienzo de la modernidad, de lenguajes cultos y populares" (p.13).

En el continente americano, los mercados populares, también denominados como galerías o mercados centrales, son un testimonio vivo de esta coexistencia, de la hibridación cultural y el mestizaje, albergando y evidenciando un conjunto de procesos socioculturales, estrechamente vinculados, como los movimientos migratorios, el encuentro de lo tradicional con lo moderno y de lo rural con lo urbano, la creolización y el sincretismo, en un encuentro de identidades culturales; recorrer estos escenarios "puede ayudar a comprender y evidenciar las culturas que en cada pueblo o ciudad habitan, sus costumbres, sus productos y sus tradiciones" (Ángel-Bravo, 2016, p.264). Es por ello, que en la presente investigación se busca comprender y analizar cómo estos fenómenos se materializan y se evidencian dentro de los mercados populares, espacios que se revalúan como núcleos de preservación cultural. 


\section{Metodología}

Este proceso investigativo, de carácter descriptivo y cualitativo, se fundamenta en el análisis morfológico de la imagen, método propuesto por Marzal (2007), a través de la descripción del motivo fotográfico. Acudiendo a la fotografía, como instrumento para la recolección y registro documental, utilizando la observación directa y haciendo revisión de diversos referentes teóricos, se busca comprender y analizar un conjunto de fenómenos socioculturales que se materializan y se evidencian dentro de los mercados populares en las regiones Norte, Centro y Sur de América, a través de una amplia diversidad de productos, artefactos, prácticas y servicios que allí se acogen.

A nivel general, el proceso de recolección de información, organización, interpretación y análisis del material gráfico, se basa en el modelo o método folklórico, propuesto por Ocampo (1981), mediante el cual se recopila el material a través de diversos medios, para su organización, clasificación e interpretación, conduciendo finalmente, a la generación de análisis y producción de nuevos saberes.

\section{El mercado popular y su valor cultural}

En el contexto continental, los mercados populares, además de ser escenarios para el intercambio comercial de productos y servicios, son de gran importancia para la preservación de diversas expresiones de carácter popular, ancestral, tradicional y folklórico (ver Figura II y III). Estos lugares no solo permiten la distribución de alimentos, puesto que en ellos es posible adquirir plantas medicinales, artículos utilitarios y decorativos de carácter artesanal, imaginería religiosa, amuletos y otros productos asociados a la superstición, entre otros. Gracias a estos elementos tangibles, propios de lo que Abadía (1983) define como folklore demosófico, es posible evidenciar y comprender la herencia alimentaria, las creencias religiosas, la espiritualidad, las tradiciones y costumbres, de cada uno de los contextos donde estos mercados se ubican.

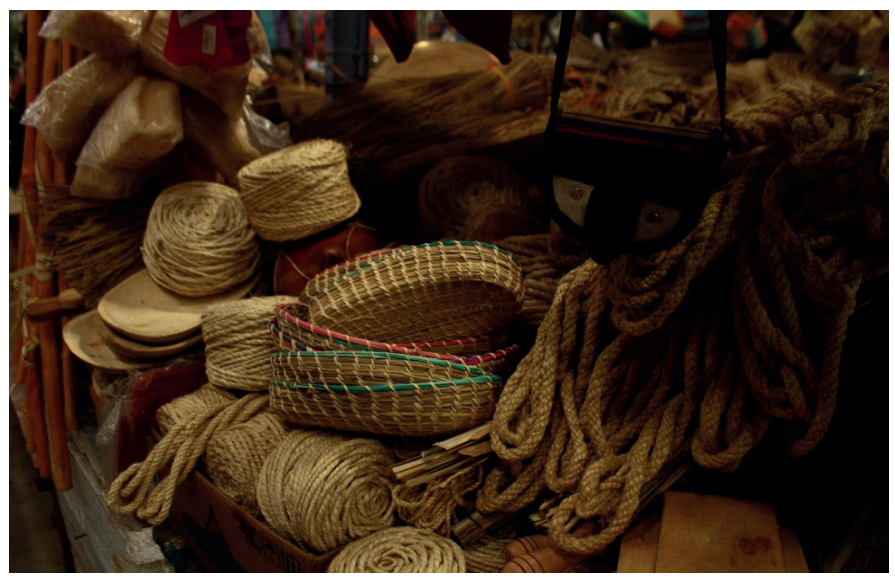

Fuente: Elaboración propia, 2018.

\section{Figura II: Artefactos utilitarios de producción artesanal. Plaza de mercado La Esmeralda, Popayán, Colombia}


Mestizaje, creolización, sincretismo e hibridación cultural, a través de los mercados populares en América

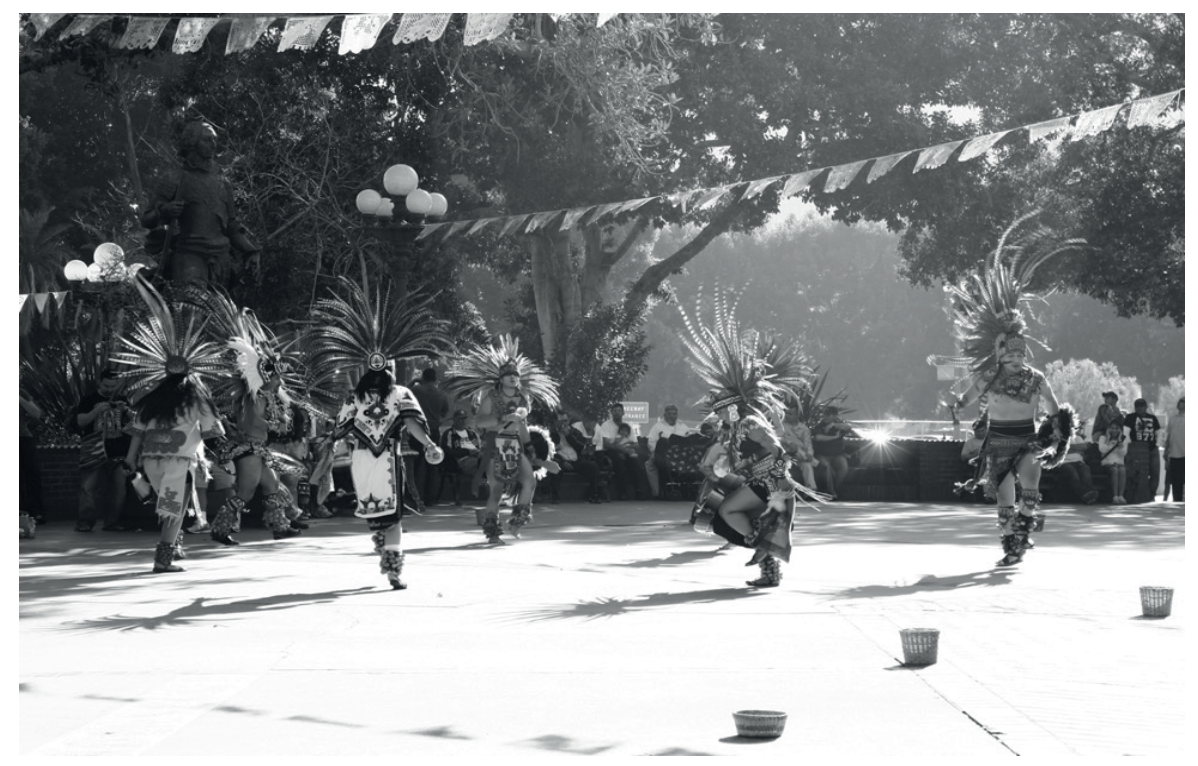

Fuente: Elaboración propia, 2012.

Figura III: Danzantes aztecas, mercado de Olvera Street, Los Ángeles, California

Al respecto, Coronado (2010), define los mercados populares, como:

(...) el sitio de encuentro entre vecinos, conservando una memoria cultural alimentaría, rica en tradiciones locales $\mathrm{y}$ regionales, base para fortalecer la identidad y la pertenencia en una ciudad plural e incluyente (...) espacios populares para intercambiar sabiduría tradicional, fomentar prácticas culturales, incrementar el sentido de pertenencia. (p.20)

Desde una aproximación estructural, el Gobierno Autónomo Descentralizado Municipal del Cantón Latacunga (GAD Municipal de Latacunga, 2012), describe este lugar como el "Centro de comercialización de alimentos que cuenta con infraestructura fija y cerrada, en la cual los comerciantes compran y venden sus productos al público en sus puestos individuales distribuidos por giros".

De acuerdo con Eames y Eames (2015), "existe cierta evidencia para indicar, que se puede juzgar el estado de la cultura en un país, por la calidad del pan y la sopa" (p.226); para estos autores, a través de los objetos, costumbres, prácticas, tradiciones, creencias y herencia alimentaria, es posible comprender la cultura e identidad de un territorio, siendo el mercado popular, desde esta aproximación, el escenario ideal para la observación y reconocimiento de estas expresiones de carácter popular y folklórico.

Estos espacios de carácter comercial y cultural, permiten reconocer en ellos la multiculturalidad que caracteriza y define en un sentido general, la identidad del continente americano, determinada por el encuentro de la 
cultura aborigen o precolombina, con la cultura europea, como lo describen Villegas (1988) y el Ministerio de Turismo de Ecuador (2020), al que se suma posteriormente, la creolización, con el tráfico de esclavos de origen africano, consolidando un proceso intercultural que inicia desde el descubrimiento y colonización del nuevo continente en el siglo XV.

\section{Antecedentes históricos: Descubrimiento y conquista}

El deseo impetuoso en el "viejo mundo", de acercar los continentes de Europa y Asia, para fortalecer y optimizar sus procesos de intercambio comercial, motiva a viajeros $\mathrm{y}$ navegantes a emprender extensas travesías marítimas a finales del siglo XV, constituyendo en primer lugar, el camino de la comunicación náutica entre los países occidentales y el oriente, proeza ejecutada por Bartolomé Díaz y Vasco de Gama, bajo el auspicio de la Corte de Portugal; el éxito de estas travesías, de gran favorabilidad para los comerciantes europeos, motiva a nuevos marinos a navegar en nuevas direcciones, buscando fortuna (Castillero, 2004)

Uno de estos exploradores, sería el navegante Cristóbal Colón, quien busca encontrar un trayecto más directo a los países de oriente, con base en la combatida idea de la redondez de la tierra, con el objetivo de llegar a lo que entonces se denominaba como Indias Orientales, navegando con dirección a occidente, en el sentido opuesto a lo que se había hecho, para finalmente, el 12 de octubre de 1492, descubrir estos nuevos territorios en el continente americano, lo que sería en aquel tiempo denominado como Indias Occidentales (Castillero, 2004). Como lo explica Saucedo (2014), la conquista, entendida como el "proceso de inserción de la cultura española" (p.33), tiene como propósito el descubrimiento de tierras nuevas, que pudieran ofrecer diversas riquezas minerales para su explotación y ocupación a estos grupos de exploradores.

Para los países de Europa occidental, finalizaba la Edad Media feudal, caracterizada por la agricultura de subsistencia, en la cual los señoríos generaban producción solo exclusivamente para el consumo de sus propios habitantes, siendo estas sociedades básicamente rurales y de población campesina. En los siglos XI y XII, se da un resurgimiento del comercio terrestre y marítimo, como de la producción artesanal, con una gran circulación comercial, la cual transforma la economía señorial, orientando la producción hacia la venta de excedentes (Montenegro y Marañón, 1985).

Luego, a mediados del siglo $\mathrm{XV}$, con el fortalecimiento de la burguesía comercial, surge un nuevo sistema económico, el capitalismo comercial; en este sistema, se invierten capitales o bienes para generar ganancias, con base en mano de obra libre. Dicho modelo económico sería, de acuerdo con Montenegro y Marañón (1985), una primera causa de la expansión europea, el descubrimiento y conquista del nuevo continente. Una segunda, de acuerdo con estos autores, radicaría en la consolidación de Inglaterra, Francia, Portugal y España, como "estados modernos bajo monarquías autoritarias y centralistas" (p.23), dentro de los cuales, cada Rey busca enriquecer su país, a través de la expansión y la colonización.

Este primer encuentro entre los navegantes de origen europeo, con los pueblos aborígenes americanos, denominados entonces bajo el calificativo genérico de "indios", se convierte en el punto de partida, para un proceso de intercambio económico y cultural, que posteriormente, sería complementado con la migración forzada de población africana, a través de la esclavitud. "La mezcla de colonizadores españoles y portugueses, luego de ingleses y franceses, con indígenas americanos, a la cual se añadieron esclavos trasladados desde África, volvió al mestizaje un proceso fundacional en las sociedades del llamado Nuevo Mundo" (García, 2001, p.21).

Denominado por García (2015), como el "sincretismo triétnico" (p.394), dicho proceso se materializa y permanece latente por medio de la conjugación de diversas creencias, rituales, amuletos, imaginería e iconografía, 
Ángel-Bravo, Rafael

Mestizaje, creolización, sincretismo e hibridación cultural, a través de los mercados populares en América

aún vigentes en los mercados populares, fuerte influencia indígena y africana (ver especialmente en regiones geográficas de Figura IV y V).

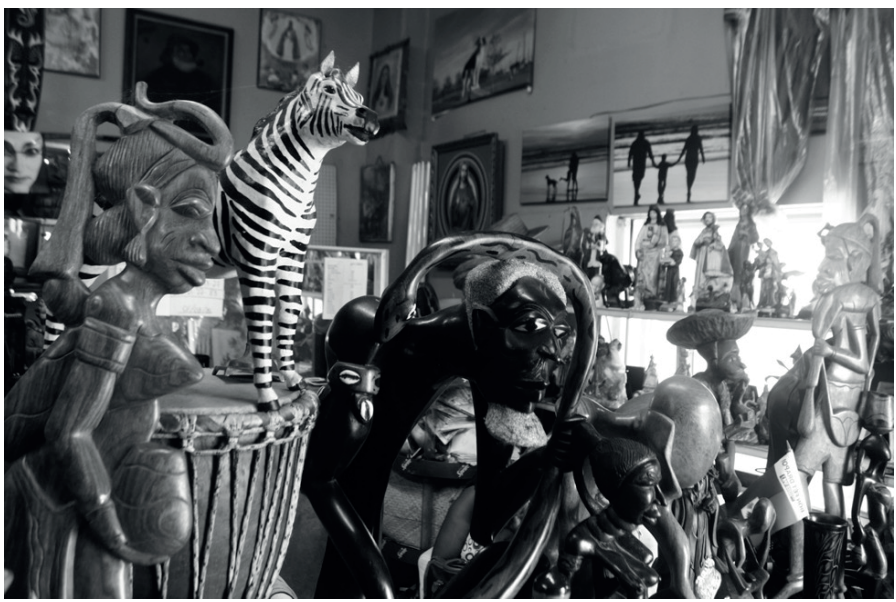

Fuente: Elaboración propia, 2016.

Figura IV: Sincretismo triétnico, materializado través de la imaginería religiosa, la magia y la superstición. Santa Bárbara Botánica, Little Haití, Miami

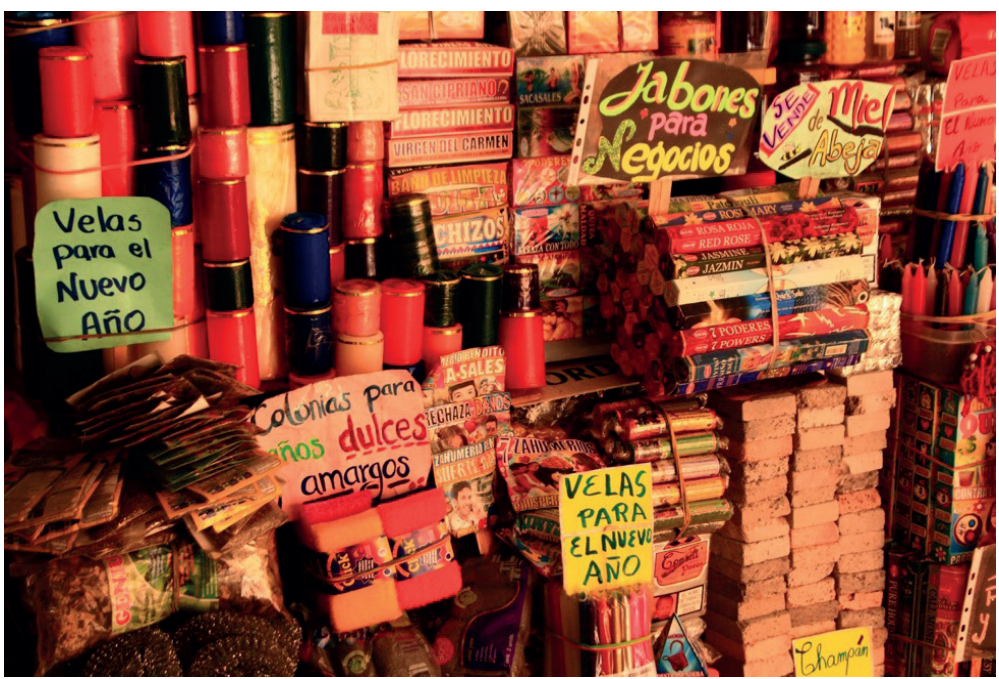

Fuente: Elaboración propia, 2018.

Figura V: Colonias, velas, jabones y otros productos asociados con la sanación y la superstición. Mercado Central, Quito, Ecuador 


\section{Mestizaje, sincretismo y creolización en el continente americano}

"¿A través de qué alquimia se mezclan las culturas?, ¿En qué condiciones? ¿Bajo qué circunstancias? ¿De qué manera y en qué medida?" (Gruzinski, 2013, p.3). De acuerdo con García (2005), la comunidad indígena o aborigen no sobrepasa el $10 \%$ de la población latinoamericana; igualmente plantea, es una minoría la urbe de origen europeo que no se ha mezclado con población nativa, lo cual implica, que un gran porcentaje de la población, especialmente en el contexto de Latinoamérica, con sus diversas expresiones, creencias e identidad, surge del mestizaje, la creolización y el sincretismo de creencias, fenómenos basados en el encuentro de las identidades precolombinas o nativas, con las culturas migrantes, europea y africana.

Estos procesos dan lugar a una mezcla intercultural, que se desarrolla y se manifiesta en diferentes proporciones, en las distintas regiones del continente, a partir de antecedentes históricos; movimientos migratorios, los cuales no siempre se dan en condiciones favorables o voluntarias, siendo a su vez un fenómeno que motiva la pluralidad, gracias al intercambio cultural que esto conlleva, como lo explican Guillén, Menéndez y Moreira (2019) y Gutiérrez, et al. (2020); factores socioculturales y económicos; entre otros; por lo tanto, dicha multiculturalidad, evidencia la presencia de estas identidades y orígenes, en mayor o menor medida, dependiendo del contexto geográfico que se analice, asumiendo cada uno de estos componentes, mayor o menor notoriedad, de acuerdo con cada territorio (Ángel-Bravo, 2018).

De acuerdo con Todorov (1986), "La interacción constante de culturas da como resultado la formación de culturas híbridas, cruzadas o creolizadas" (p.20), siendo exitosa en la medida que da lugar a una coexistencia, a un proceso de intercambio fluido y recíproco, en el cual según Schmidt (2004), se conservan las fronteras, pero se enriquecen las culturas involucradas, como en el caso de la conquista y colonización del continente americano, por parte de los españoles, calificándola como una "coexistencia de diferentes lenguajes y culturas" (p.228).

Como lo explica García (2001), la historia de las fusiones en diferentes grupos, requiere el concepto de mestizaje en un sentido biológico, entendido como la "producción de fenotipos a partir de cruzamientos genéticos" (p.21), como en un sentido cultural, tal como sucede en la mezcla de algunos hábitos, creencias y formas de pensamiento, de los inmigrantes europeos, frente a aquellos que se originan en las sociedades americanas.

Si bien, existe una estrecha relación entre los conceptos de mestizaje y sincretismo, Schmidt (2004) explica que "el primero se dirige exclusivamente a la mezcla racial, mientras que el segundo se caracteriza por la mezcla de movimientos simbólicos religiosos o, mejor dicho, tradicionales" (p.229). Por su parte, García (2001) describe el sincretismo como "la combinación de prácticas religiosas tradicionales" (p.21), la cual se incrementa con la intensificación de las migraciones y la difusión transcontinental, durante el último siglo, siendo común la posibilidad de las múltiples pertenencias religiosas, fenómeno que se extiende en algunos casos, más allá de las prácticas religiosas, con el fin de comprender diversos tipos de creencias, que pueden estar asociadas con la medicina ancestral, la magia, la superstición y diversos rituales para la prosperidad (ver Figura IV y V).

Respecto al fenómeno del sincretismo, Gutiérrez (2014) lo define como el proceso de "apropiarse y rehacer lo ajeno para fundirlo y confundirlo con lo propio" (p.126); frente a esto, Rowe y Schelling (1991) explican que, si se considera el sincretismo en un sentido más general, como la adhesión simultánea a diversos sistemas de creencias, no solo religiosas, dicho fenómeno se hace mucho más complejo, sobre todo en las comunidades que recurren a medicinas indígenas $\mathrm{u}$ orientales para ciertas enfermedades, en otros casos, a la medicina alopática, amalgamados con imaginería y rituales católicos, como de otras religiones o credos. 
Mestizaje, creolización, sincretismo e hibridación cultural, a través de los mercados populares en América

Estos recursos, relacionados con la medicina natural y la sanación, como lo explica Uribe (2012), suelen asociarse con fusiones musicales y formas multiculturales de organización social, como se puede apreciar en prácticas como la santería cubana, el vudú haitiano (ver Figura IV) y prácticas diversas donde se encuentran los saberes de la medicina ancestral, la religión, la espiritualidad y la superstición (ver Figura VI y VII).

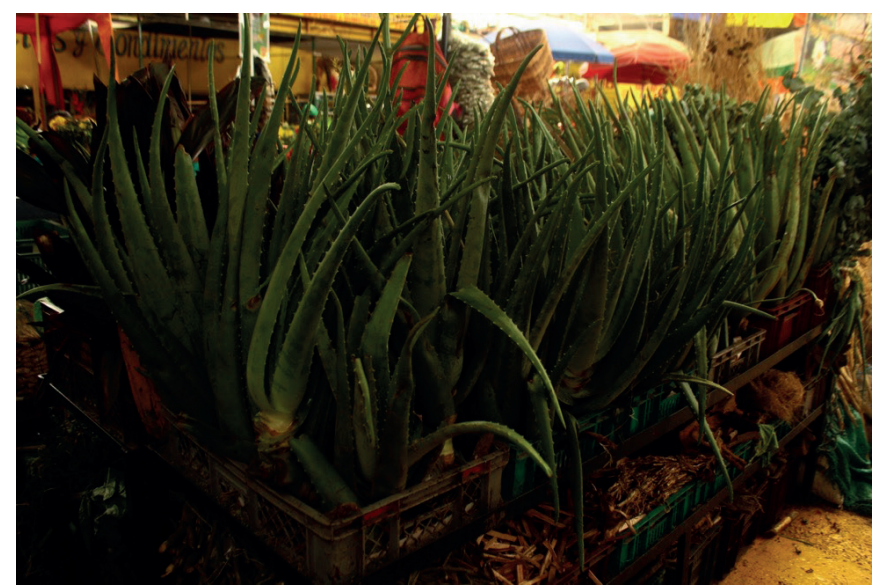

Fuente: Elaboración propia, 2018.

Figura VI: Aloe Vera y otras plantas, asociadas con la medicina y la superstición. Plaza de Mercado, Palmira, Colombia

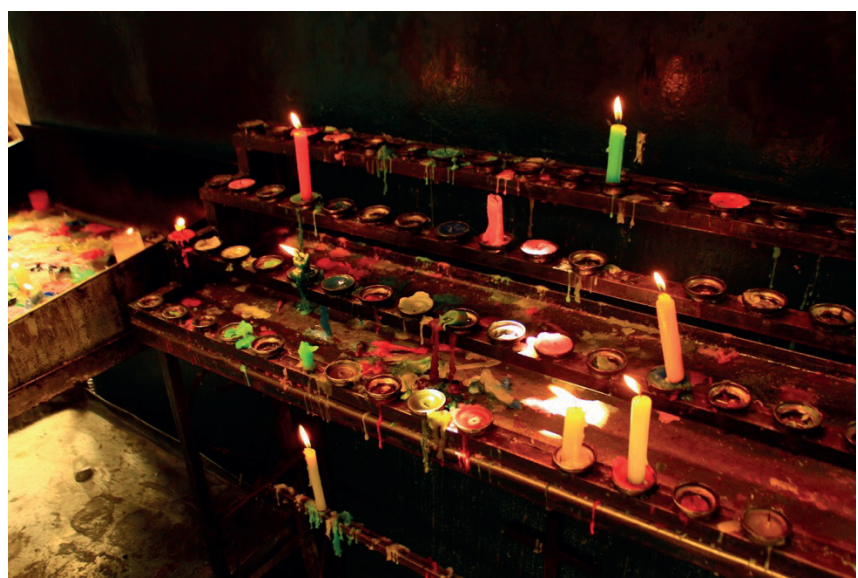

Fuente: Elaboración propia, 2018.

Figura VII: Altar católico dentro del mercado popular. Plaza de Mercado El Potrerillo, Pasto, Colombia 
Dentro del folklore demosófico, como lo expone Abadía (1983), las prácticas esotéricas de brujos, hechiceros, yerbateros, chamanes, chupadores, curanderos y sobanderos, entre otros apelativos, rituales sagrados y ciencia empírica, dan lugar a un sincretismo entre las creencias religiosas, la superstición y la medicina natural, el cual se gesta a partir del mestizaje triétnico y la creolización, con base en la integración de los saberes ancestrales de origen precolombino, manifestaciones e iconografía propias de catolicismo europeo, como las creencias y prácticas propias de la cultura africana.

Estos productos, expresiones y prácticas, encuentran en la plaza de mercado o mercado popular, un canal para su difusión, comercialización y preservación, siendo un espacio donde conviven estás manifestaciones y creencias, sincretizadas con las costumbres, rituales e iconografía del catolicismo, teniendo este último, una presencia permanente en estos lugares, a través de altares, capillas e imaginería religiosa (ver Figura IV y VII).

Aun cuando la conquista y sus procesos interculturales derivados, afectan de manera general al continente americano, sostiene García (2015) que: "El sincretismo triétnico (indígenas, africanos y españoles) es la base cultural y racial de la población caribeña" (p.394), explicando que, por su ubicación geográfica, actividades comerciales y turísticas, el Caribe ha estado sujeto a diversos movimientos migratorios, proponiendo el concepto de "caribe" en lugar de "africano", dentro del contexto del mestizaje, con el fin de denominar la cultura resultante de estos procesos de mestizaje o creolización.

En ese sentido, García (2015) considera lo caribe como "una síntesis humana, étnica y cultural, que no se reduce a ninguno de sus componentes, pues se trata de una nueva expresión, el resultado complejo de la relación desigual de varios elementos" (p.402). Desde esta perspectiva, el sincretismo es planteado en un sentido más intrincado, donde el encuentro de las culturas precolombinas, con las culturas europea y africana, dan como resultado una nueva identidad, más allá de lo estrictamente religioso o espiritual (ver Figura VIII).

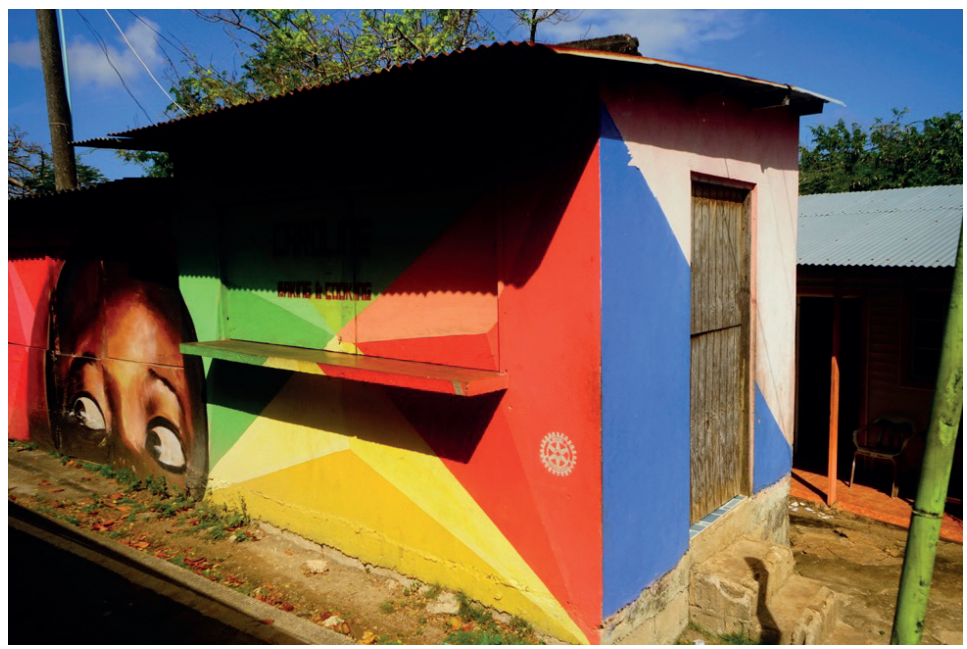

Fuente: Elaboración propia, 2020.

Figura VIII: Creolización, cocina tradicional y arte popular en el Caribe colombiano. Caroline Baking and Cooking, San Andrés, Colombia 
Aunque el concepto de creolización o criollización, se ha utilizado de manera general para referirse a mezclas interculturales, en un sentido estricto, este término permite definir al lenguaje y cultura, creados por variaciones de un lenguaje base y otros lenguajes, en el contexto del tráfico de esclavos, desde el continente africano (García, 2005). La llegada de estos grupos humanos, a partir de la esclavitud y otros procesos migratorios, han llevado a la consolidación, en territorio americano, de movimientos culturales y expresiones artísticas diversas como el vallenato, la salsa, el reggae y el hip hop, entre muchas otras, al igual que ha contribuido al sincretismo de creencias, hoy visible a través de las llamadas "botánicas" (ver Figura IV) y mercados populares en general (ver Figura V).

Finalmente, aun frente a las diferencias semánticas, establecidas entre los conceptos de mestizaje, sincretismo y creolización, es inevitable establecer un rompimiento o separación absoluta entre ellos, siendo todos consecuencia, en gran medida, de la expansión europea y su colonización del continente americano.

\section{Hibridación cultural: Una familia de conceptos}

García (2001), define la hibridación como los "procesos socioculturales en los que estructuras o prácticas discretas, que existían en forma separada, se combinan para generar nuevas estructuras, objetos y prácticas" (p.14). Asimismo, plantea que, dichas estructuras son el resultado de hibridaciones previas, por lo cual, no pueden ser consideradas como puras. Partiendo de esto, es necesario comprender, que las diversas expresiones populares, lenguas, tradiciones, costumbres e identidades de los pueblos, se configuran por medio del encuentro de estructuras aisladas, las cuales a su vez se conforman sobre la base de mezclas o mestizajes anteriores, y que posteriormente, servirán para la generación de nuevas organizaciones híbridas.

Esta evolución de estructuras aisladas a estructuras híbridas, definido en García (2001) como la fórmula de los "ciclos de hibridación" (p.15), describe cómo a través de la historia se genera una transición de formas más heterogéneas hacia otras más homogéneas, para después evolucionar nuevamente hacia otras formas relativamente homogéneas, sin ser ninguna de ellas "pura" o simplemente homogénea.

De acuerdo con García (2005), la hibridación cultural abarca fenómenos dispares y situaciones diversas, presentes desde el despertar mismo de la globalización; en ese sentido, el concepto de hibridación es utilizado en algunas investigaciones para denominar diversas formas de contacto intercultural, usualmente mencionadas bajo distintos nombres, incluyendo el mestizaje de etnias, el sincretismo de creencias, el encuentro de lo artesanal con lo industrial, lo culto y lo popular, así como la combinación de lenguajes escritos y visuales, en los medios masivos de comunicación.

Conceptos como mestizaje, sincretismo y creolización, siguen siendo utilizados en literatura antropológica para denominar diversas formas de hibridación cultural, mientras que, el concepto de hibridación, permite identificar fenómenos modernos que se desarrollan principalmente en territorios fronterizos y grandes ciudades, en muchos casos asociados con los desarrollos tecnológicos, designando de esta manera a la fusión entre los medios masivos y la cultura popular, entre lo local y lo global, en gran medida determinados o fortalecidos por la globalización, los desarrollo en comunicaciones y los movimientos migratorios (García, 2001).

\section{Tradición e identidad frente a la modernidad y la globalización}

La exigencia de un molde universal, la estandarización del mundo así como el decaimiento de una realidad, "reducida a mercancía, perfectamente podría ir de la mano, con un pluralismo imaginario, con una ilusoria 
diversidad, mantenida a cualquier costo, de hecho, reconstruida y confeccionada fuera de la realidad" (Gruzinski, 2013, p.3).

Con el inicio de la industrialización, a comienzos del siglo XX, se da una transición de la producción artesanal, a la tecnificada o en serie; igualmente, se produce una transición de las sociedades rurales o campesinas, a urbanas, modernas e industrializadas, motivando la conformación de las grandes ciudades, alrededor de estos nuevos procesos productivos, los cuales entran a estandarizar la fabricación de artefactos utilitarios y decorativos, colocando en riesgo el trabajo de artesanos y campesinos, cuya labor es relegada a un plano secundario, frente a una producción tecnificada y homogeneizada.

En el continente americano, especialmente en las regiones centro y sur, comunidades rurales y urbanas, al igual que los procesos artesanales y procesos tecnificados de producción, coexisten y conviven hasta el día de hoy, desarrollándose de forma paralela, encontrando en los mercados populares su punto de encuentro, donde se construye un diálogo entre lo local y lo global, lo artesanal y lo industrial, entre la tradición y la modernidad. Frente al posible impacto de estas nuevas tecnologías y procesos, en la producción artesanal y el patrimonio cultural,
Villegas (1988) señala que:

En estos tiempos, el avance de los medios de comunicación y la concentración tecnológica aumentan día a día, con lo cual el universo de los objetos tiende a estandarizarse. Entonces, también su identidad va perdiéndose o pasa inadvertida, entre otras razones, por la ausencia de una tradición cultural sólida y propia. -tras la desaparición de la indígena y la adaptación de la europea- que nos alejó de nosotros mismos. (p.7)

"Nuestras ciudades son esa mezcla, están repletas de campesinos recién llegados, aunque haya sido hace 20 años", así define García (2003) la ciudad latinoamericana, como un espacio de encuentro entre lo rural y lo urbano, lo local y lo global, en el cual se manifiesta su herencia precolombina y campesina, en contraste con las tendencias homogeneizadoras de la globalización y la modernidad, a través del encuentro de artefactos, productos, costumbres, tradiciones y creencias propias de cada territorio o región, con diversas expresiones foráneas (ver Figura IX y X), que se expanden gracias a los procesos migratorios y los grandes avances tecnológicos en las comunicaciones, desde el siglo $\mathrm{XX}$.

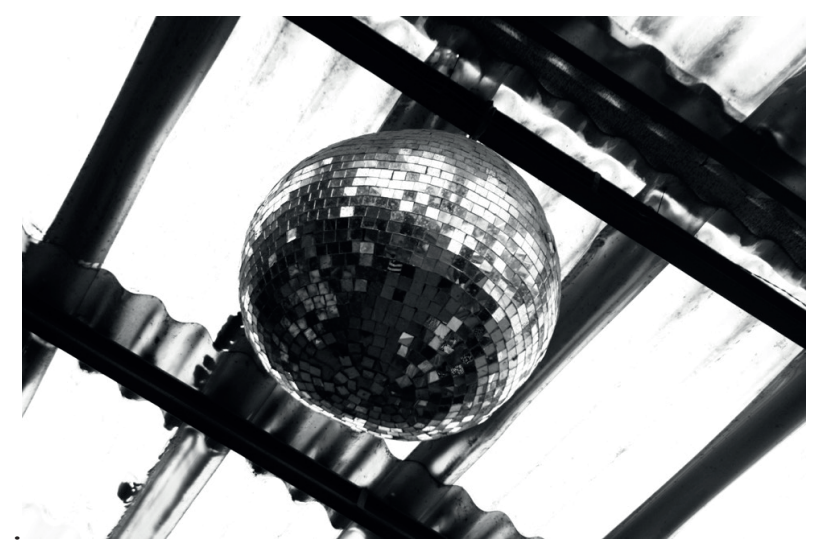

Fuente: Elaboración propia, 2018.

Figura IX: Bola disco colgando en medio del mercado popular. Plaza de Mercado El Potrerillo, Pasto, Colombia 


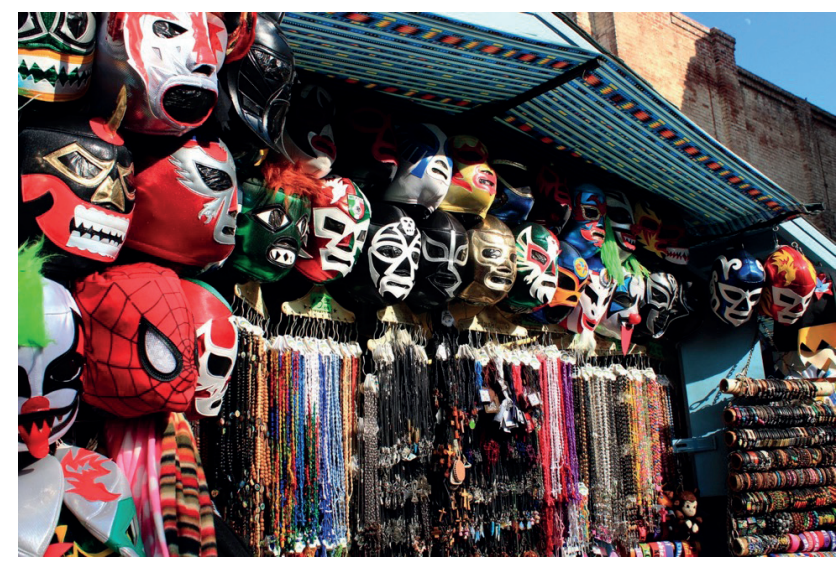

Fuente: Elaboración propia, 2012.

\section{Figura X: Artículos propios de la cultura mexicana son comercializados en el mercado popular. Olvera Street, Los Ángeles, California}

En palabras de García (2002), "la globalización tiende a uniformar el mercado y a estandarizar patrones comunes" (p.18), considerando este proceso como consecuencia de un "conjunto de procesos sociales, económicos, tecnológicos, que no suceden por azar (...) de un conjunto de tendencias históricas, del discurso neoliberal, que pretende homogeneizar o subordinar mercados o formas culturales locales a un proyecto que se presenta como mundial" (p.18).

Tal como sucede en su momento con la industrialización, relegando o colocando en riesgo el trabajo de artesanos con la implementación de nuevos procesos automatizados o de producción en cadena; la modernidad y la globalización tienden a desplazar las expresiones vernáculas, tradicionales y folklóricas, para imponer modelos, estéticas y expresiones globales.

Frente a estos procesos de industrialización y modernidad, en contextos urbanos, Martín-Barbero (1981), define la plaza de mercado como un espacio "aún no homogeneizado ni funcionalizado completamente, aún no digerido por la maquinaria mercantil" (p.4), siendo este un escenario propicio para la preservación de diversas manifestaciones de la producción artesanal, la tradición alimentaria, la espiritualidad y la superstición.

Los mercados populares y artesanales en el continente americano, han ayudado a la conservación del patrimonio material e inmaterial, protegiendo estas técnicas y formas de producción, de carácter empírico, popular y tradicional, entregadas y preservadas de generación en generación, las cuales no solo se enfrentan a unas nuevas formas de producción, tecnificadas o industrializadas, sino a los efectos uniformadores $u$ homogeneizadores de la globalización y la modernidad, la cual tiende a estandarizar patrones estéticos, formales y culturales comunes.

Además de convertirse en un espacio de intercambio social y comercial para cada comunidad, los mercados populares se establecen como un punto de encuentro entre las sociedades rurales y urbanas, la tradición y la modernidad, entre lo local y lo global, trascendiendo para convertirse en mucho más que simples lugares de intercambio comercial.

Entre la producción artesanal y la industrialización de los procesos, los 
productos, artefactos y servicios, que en estos lugares se distribuyen, como las prácticas y costumbres que allí se manifiestan, desde el arte, la superstición, la sanación y la espiritualidad, dan cuenta de unos saberes populares y ancestrales que son comunicados por medio de la tradición oral, de forma generacional, permaneciendo vigentes en el tiempo, en contraposición frente a los efectos homogeneizadores de la globalización, la cual, desarrollada sin límites o controles, puede colocar en riesgo este patrimonio cultural o ayudar al reconocimiento de la diversidad cultural del continente, si se asume de una manera sostenible y responsable frente a su patrimonio.

Espinoza y Ley (2020), plantean la necesidad de espacios y estrategias que permitan la convivencia armónica de diversas identidades y la protección de la riqueza cultural, dentro de estos contextos multiculturales. De un desarrollo responsable y sostenible, respetuoso del folklore y el patrimonio cultural, dependerá finalmente la preservación de estas identidades, sus saberes, sus costumbres y sus tradiciones.

\section{Conclusiones}

Los diversos procesos de desplazamiento humano y migración, incluyendo entre ellos la expansión europea hacia el continente americano, conquista y colonización, al igual que el tráfico y movilización de esclavos, traen como consecuencia un conjunto de fenómenos asociados al intercambio étnico y cultural, tales como el mestizaje, la creolización, el sincretismo y la hibridación, los cuales conducen a un encuentro y fusión de culturas, tradiciones, costumbres, prácticas y creencias, que dan como resultado la configuración o reconfiguración de unas nuevas identidades culturales, que evolucionan gradualmente, siendo afectadas en muchos casos, por los avances tecnológicos en las comunicaciones, los desarrollos en el transporte y los efectos homogeneizadores de la globalización.

Estas identidades dinámicas $\mathrm{y}$ cambiantes, definidas a partir de los procesos interculturales que a nivel continental se desarrollan, encuentran en el mercado popular un escenario de preservación y resistencia, frente a las tendencias, modelos y patrones globales, neutralizando la estandarización de patrones estéticos, formales y culturales, permitiendo la armonía de diversas identidades así como la protección de la riqueza cultural, dentro de estos contextos multiculturales.

De igual manera, los procesos migratorios y de desplazamiento entre distintos países, a nivel continental, especialmente hacia América del Norte, conducen a la conformación de núcleos de expresión cultural, guetos o comunidades, los cuales, más que espacios de residencia, son territorios que permiten la preservación de las diversas identidades, propias de estos grupos migrantes, incluyendo su herencia alimentaria, tradiciones, costumbres, creencias, músicas y otras expresiones artísticas. Adicionalmente, estos lugares, aunque permiten la conservación de estas identidades, son también un espacio que consienten la hibridación y el intercambio cultural, a partir del encuentro de saberes que se establece entre las comunidades inmigrantes y las poblaciones locales, previamente allí establecidas.

Parte fundamental en la conformación de estas comunidades, reside en la creación de escenarios para el desarrollo de sus creencias espirituales, supersticiosas y religiosas, como en la apertura de mercados populares, a través de los cuales se comercializan sus productos típicos o tradicionales, siendo estos el espacio de encuentro para estas comunidades, como el escenario ideal para la preservación de estas identidades cambiantes.

Frente a las diversas interpretaciones semánticas asociadas a los conceptos de mestizaje, creolización, sincretismo e hibridación, en el contexto latinoamericano, es necesario comprender que todos ellos responden a un proceso de encuentro o fusión intercultural, que se construye a partir del intercambio racial o étnico entre las culturas indígenas, aborígenes, prehispánicas o precolombinas, establecidas a lo largo de este 
Mestizaje, creolización, sincretismo e hibridación cultural, a través de los mercados populares en América

territorio, con las culturas europea y africana, las cuales se entrelazan en una síntesis humana, étnica y cultural, que da como resultado una configuración y reconfiguración permanente de identidades, las cuales permanecen en constante evolución y transformación, gracias en parte, a los movimientos migratorios.

Entendiendo la creolización o criollización como el proceso intercultural derivado del tráfico de esclavos de origen africano, del cual se obtiene como resultado una nueva identidad "caribe", es necesario comprender este fenómeno como un proceso inherente al continente americano en su totalidad, a través del cual, en mayor o menor medida influye el mestizaje triétnico como base para la configuración de su identidad y su patrimonio cultural, especialmente protagónico en las prácticas de carácter mágico, como espiritual, en las cocinas tradicionales, así como en una gran diversidad de expresiones artísticas y musicales que se desarrollan en Norte, Centro y Sur América.

Dentro de los distintos fenómenos interculturales y conceptos que se originan a partir del mestizaje, el sincretismo, como encuentro o fusión de creencias y expresiones de la religiosidad, es el de mayor notoriedad en el contexto de los mercados populares a nivel continental, puesto que, gracias a las medicinas ancestrales, amuletos y creencias basadas en la magia y la superstición, así como la iconografía, creencias y prácticas propias del catolicismo, se construyen nuevas identidades, creencias y concepciones de la sanación y el bienestar humano, a partir de esta conjugación de saberes, transferidos en gran medida por medio de la oralidad, en conjunto con los procesos migratorios y siendo preservados a través de estos espacios de intercambio comercial y social.

\section{Referencias bibliográficas}

Abadía, G. (1983). Compendio general del folklore colombiano. Biblioteca Banco Popular.
Ángel-Bravo, R. (2016). Galerías y plazas de mercado como espacio de conservación cultural y producción audiovisual. Nexus Comunicación, (20), 246$267 . \quad$ https://doi.org/10.25100/ nc.v0i20.1843

Ángel-Bravo, R. (2018). La galería o plaza de mercado como expresión de diversidad y espacio de conservación cultural en el continente americano. SID10. Seminario Internacional de Investigación en Diseño, Popayán, Cauca, Colombia.

Castillero, E. J. (2004). Historia general de Panamá. Editora Nacional. Comité Nacional del Centenario.

Coronado, M. C. (2010). Plazas de mercado: Una tradición continua. Apuntes Revista Digital de Arquitectura, (22). http://apuntesdearquitecturadigital. blogspot.com/2010/12/plazas-demercado-una-tradicion.html

Eames, C., y Eames, R. (2015). An Eames anthology: Articles, film scripts, interviews, letters, notes, and speeches. Yale University Press.

Espinoza, E. E., y Ley, N. V. (2020). Educación intercultural en el Ecuador: Una revisión sistemática. Revista de Ciencias Sociales (Ve), XXVI(2), 275-288. https://doi.org/10.31876/rcs. v26i0.34127

García, J. (2015). Cultura y competitividad: ¿cómo reforzar la identidad caribe de Cartagena? En A. Abello y F. J. Flórez (Eds.), Los desterrados del paraíso: Raza, pobreza y cultura en Cartagena de Indias (pp. 378-421). Editorial Maremágnum.

García, N. (2001). Culturas híbridas: Estrategias para entrar y salir de la modernidad. Editorial Paidós.

García, N. (2002). Entrevista con Néstor García Canclini I. La iniciativa de comunicación. http://www.comminit. 
com/la/node/67260

García, N. (2003). Entrevista con Néstor García Canclini II. La iniciativa de comunicación. http://www.comminit. com/node $/ 67264$

García, N. (2005). Hybrid cultures: Strategies for entering and leaving modernity. University of Minnesota Press.

Gobierno Autónomo Descentralizado Municipal del Cantón Latacunga - GAD Municipal de Latacunga (2012). Ordenanza municipales. Cantón Latacunga: Que reglamenta la ocupación del mercado cerrado de Latacunga. https://vlex.ec/vid/ canton-latacunga-ocupacion-mercadocerrado-420572030

Gruzinski, S. (2013). The mestizo mind: The intellectual dynamics of colonization and globalization. Routledge.

Guillén, J. C., Menéndez, F. G., y Moreira, T. K. (2019). Migración: Como fenómeno social vulnerable y salvaguarda de los derechos humanos. Revista de Ciencias Sociales (Ve), XXV(E-1), 281-294. https://doi.org/10.31876/rcs. v25i1.29619

Gutiérrez, M. (2014). Otra vez sobre el sincretismo. ÉNDOXA: Series Filosóficas, (33), 119-141. https://doi. org/10.5944/endoxa.33.2014.13557

Gutiérrez, J. M., Romero, J., Arias, S. R., y Briones, X. F. (2020). Migración: Contexto, impacto y desafío. Una reflexión teórica. Revista de Ciencias Sociales (Ve), XXVI(2), 299313. https://doi.org/10.31876/rcs. v26i2.32443

Martín-Barbero, J. (1981). Prácticas de comunicación en la cultura popular: Mercados, plazas, cementerios y espacios de ocio. En M. Simpson
(Comp.), Comunicación alternativa y cambio social (pp. 32-53). UNAM.

Marzal, J. (2007). Propuesta de modelo de análisis de la imagen fotográfica. Descripción de conceptos contemplados. ITACA-UJI. http:// www.analisisfotografia.uji.es/ root $2 / \mathrm{METODOLOGIA \% 20}$ ANALISIS \%20FOTO \%2023-112007.pdf

Ministerio de Turismo de Ecuador (2020). La gastronomía ecuatoriana al alcance de todos. Ministerio de Turismo. https:// www.turismo.gob.ec/la-gastronomiaecuatoriana-al-alcance-de-todos/

Montenegro, A., y Marañón, M. (1985). Historia y geografia resumidas: América y antiguo continente. Norma.

Ocampo, J. (1981). El folclor y los bailes típicos colombianos. Biblioteca de Escritores Caldenses.

Rowe, W., y Schelling, V. (1991). Memory and modernity: Popular culture in Latin America. Verso.

Saucedo, J. I. (2014). Poder político y jurídico en Yucatán en el siglo XVI. UNAM, Instituto de Investigaciones Jurídicas.

Schmidt, B. E. (2004). Hibridación religiosa en Nueva York. Espiritismo puertorriqueño como ejemplo del proceso híbrido. Boletín de Antropología, 18(35), 226-243.

Todorov, T. (1986). Le croisement des cultures. Communications, 43, 5-26. https://doi. org/10.3406/comm.1986.1637

Uribe, M. M. (2012). Conceptos viajeros en ciencias sociales: hibridación. Katharsis, (13), 25-36.

Villegas, L. (1988). Arte factos: Elementos de la vida cotidiana del Viejo Caldas. Villegas. 